\title{
TRIZ Tool for Optimization of Airport Runway
}

\author{
K. Venkata Rao ${ }^{1}$, V. Selladurai ${ }^{2}$, and R. Saravanan ${ }^{3}$ \\ ${ }^{1}$ Department of Mechanical Engineering Mahalingam College of Engg. \& Tech., Pollachi \\ ${ }^{2}$ Department of Mechanical Engineering Coimbatore Institute of Technology, Coimbatore \\ ${ }^{3}$ Department of Mechanical Engineering Karpagam University, Coimbatore \\ $\{$ K.Venkata Rao,Dr.V. Selladurai,R. Saravanan, \\ k_venkatarao\} @yahoo.com
}

\begin{abstract}
TRIZ tool is used for conceptual design and layout of the novel ascending and descending runway model for the effective utilization of short length airports. Handling bigger aircrafts at smaller airports become the necessity for economic consideration and for the benefit of vast airliners and the aspiring air travelers of the region. The authors' proposal of ascending and descending runway would enable the operational need of wide body aircrafts such as Boeing 747 and Airbus A380-800. Negotiating take-off and landing of bigger aircrafts at less than 10000 feet runway is an optimization solution. This conceptual model and the theoretical design with its layout is dealt in this paper as Part - I. The computer-aided design and analysis using MATLAB with Simulink tool box to confirm the adequacy of the runway length for the bigger aircrafts at smaller airports is however dealt in subsequent papers.
\end{abstract}

Keywords: TRIZ, Optimization, Ascending, Descending, Airport, Runway.

\section{Introduction}

Bigger aircrafts like Jumbo 747 and airbus A380-800 are most economical for both the operators and for the travelers. The operations of such aircrafts are otherwise required long runways and other paraphernalia at the airports. India has 128 airports, mostly built in the middle of last century. When LCC (Low cost carriers) had taken the skies in the year 2003, the Indian cities that were never been on the active air map, have been connected aggressively by many airlines looking for newer markets. The likely relaxations of five year norm for domestic airlines to fly on international routes bring great hope and promises to operate long haul flights with bigger aircrafts. The Airport Authority of India (AAI) is planning to make good investments to expand and modernize about 35 non-metro airports in the near future. Coimbatore airport is one such airport in the development map for the benefits of many airliners and air travelers. However expansions of many small runway Indian airports are just impossible because of the reason that the locations of those airports have become the centre of the cities in the last 20 years of city development. Presently the acquisitions of land for the existing airport developments has become a trivial issue causing 
inordinate delay and long hold on litigation. With those constraints and technical contradictions TRIZ tool was used to find solutions for enabling the bigger aircrafts to land and take off easily on those short length runway airports. The outcome is the ascending and descending runway model.

\section{Literature Support}

Genrich Altshuller's literature [5] provides scientific lead and step by step procedure (TRIZ algorithm) for making innovative engineering solution for many problems. The technical literatures $[4,7,9]$ which used TRIZ as a tool have enough strengths and evidences to adopt the same tool for the airport design as well. Antonio [1], Glushkov [6] and Khanna et. al.[8] prepared exclusive documents and text books for the design and estimation of runway lengths at airports. In airport design, runway occupancy time (ROT) was the topic of research and development for the last few decades by many expert airport designers and planners. Byung J. Kim et.al. [2] made designs and prepared extensive documents for the capacity improvement of airports. While all their attentions for airport developments were focused on reducing the runway occupancy time by rapid exit runway etc., the authors' attempt is on the very basic runway itself. The FAA and ICAO's safety regulations stipulate the aircraft separation of 4 to 8 nautical miles in the series of landing process. Under this condition, the rapid exit of the aircraft from the runway within 50 seconds is of no big deal. Instead a rapid exit combined with a definite stoppage of the aircraft with the optimum run on the runway length is required to be aimed and achieved. Clarke et.al [3] advocate constant descent approach of aircrafts to save fuel and to reduce noise as pollution. His theory also supports the ascending and descending runway largely. All those literatures summarily appreciate the design of ascending and descending runway model on many accounts.

\section{Triz - Theory of Solving Inventive Problems}

TRIZ is an acronym in Russian language which means theory of solving inventive problems. It is a modern theory considering engineering problems and suggests solutions based on their own built in structures. TRIZ highlights, that technical systems evolve through increasing ideality by overcoming contradictions, mostly with minimal introduction of resources. Most of such solutions though appear as innovations that are only the transpositions of known solutions in the same fields of interest. TRIZ teaches ARIZ, the Algorithm for solving inventive problems which is a sequentially structured action for invention. ARIZ divides the creative problem in to three stages namely analytical, operative and synthetic. The various steps bring forth the technical contradiction of the problem to form the matrix which is primarily used at the data base of known solutions called TRIZ principles. The 39 parameters or features that are described as input to form contradiction to be placed in the $39 \times 39$ square matrix provide selective solution among the 40 inventive principles. The algorithm for invention, matrix and the 40 principles are based on the works of a Russian scientist Genrich Altshuller. Those principles when applied judiciously would able to overcome contradictions and bring near ideal solutions. 
The parameters that are considered fit in the incident airport runway study are

(1) Area of stationary object and

(2) Loss of time.

When these two parameters put into consideration at the contradiction matrix the following four principles were emerged as possible solutions.

- Preliminary action

- Parameter changes

- Another dimension and

- Asymmetry

These four principles when applied meticulously will contribute final innovative solutions solving the contradiction.

Under the first principle of "preliminary action", the suggested solution leads to

- Perform some functions before hand

- Make required change in the area of stationary object and

- Pre-arrange objects

In a way the conditions can come into action from the most convenient place without losing time for its delivery. The resulting solutions optimally bring the concept of providing inclined slope at the end of the airport runway to offer resistance for increasing the deceleration of aircraft on its final free and sliding roll.

The second principle of "parameter changes", suggested

- Change the concentration or consistency

- Provide degree of flexibility

This suggestion validates the consistent increase of resistance through constant gradient by certain degree of slope in the ascending runway. The degree of flexibility means the different diversified runway paths available for the aircraft to roll down to its final stop at ease.

The third principle of “another dimension", brought forth

- Move an object in two or three dimensional space and

- Tilt or re-orient the object or lay it on its side.

This clearly accepts the building up of the third dimension to the runway with a constant slope of 2.5 degree in vertical direction ( $\mathrm{Z}$ plane). In addition a rapid exit runway diversion of 18 to 22.5 degrees from the main runway orientation with a slope of lesser magnitude say 2.0 degree in the vertical direction configures the ascending runway of the above suggestion.

The fourth principle of "asymmetry", dictates

- Change of shape of the object from symmetrical to asymmetrical.

This identifies the hitherto conceived concept of level runway into ascending and descending runway model. 


\section{Aircraft Landing and Take-Off Sequences}

The process of aircraft landing on the runway is generally classified into four distinctive stages. They are (1) flare and touchdown, (2) first free roll, (3) deceleration (brake / thrust reversal) and (4) turnoff to rapid exit taxi way and stop.

The process of aircraft take-off on the runway consists of only two stages, namely (1) acceleration of air craft to the required velocity for air lift (2) clearing of aircraft from the runway by elevating to 11 meters above the ground level before reaching the point of threshold.

The Figure 1 illustrates the details of the ascending and descending runway model. The estimation of travel distance and time for each stage of the landing and take - off processes are worked out theoretically. The calculations made here are pertaining to Airbus 380-800 types of aircraft only.

\subsection{Flare and Touch Down}

Aircrafts normally manoeuvre in air at about 15 meters above the ground level at the point of runway threshold prior to reach the ground level at the touchdown point of the runway. Thus the flare distance $\left(S_{\text {air }}\right)$ is defined as the distance between the threshold point and the touchdown point on the runway. It is determined using the standard equation. The aerodynamic drag on the aircraft is conveniently neglected for ease of calculation at this moment as it invariably favours otherwise.

$$
S_{\text {air }}=\frac{H_{T}}{\tan \gamma}
$$

Where

$\mathrm{S}_{\text {air }} \quad=$ runway (air) distance to touch down

$\mathrm{H}_{\mathrm{T}} \quad=$ aircraft height at threshold point

$\tan \gamma=$ descent angle of the aircraft (usually 2.5 degree for the normal approach)

The time taken for the flare stage shall be calculated using the equation:

$$
T_{a i r}=\frac{S_{a i r}}{V_{f l}}
$$

here

$\mathrm{V}_{\mathrm{fl}}=$ landing speed of the aircraft (usually taken as 1.1 to 1.15 times the stalling speed of the aircraft. For Airbus $380-800$ it is about 240 to $253 \mathrm{kmph}$ or 67 to $70 \mathrm{~m} / \mathrm{Sec}$.)

The stalling speed of the various aircrafts with maximum landing weight (MLW) at sea level can be found from the aircraft manufacturer's manual. However the changing atmospheric conditions from ISA and the location altitude determine the stall speed $\mathrm{V}_{\text {stall }}$ as, 


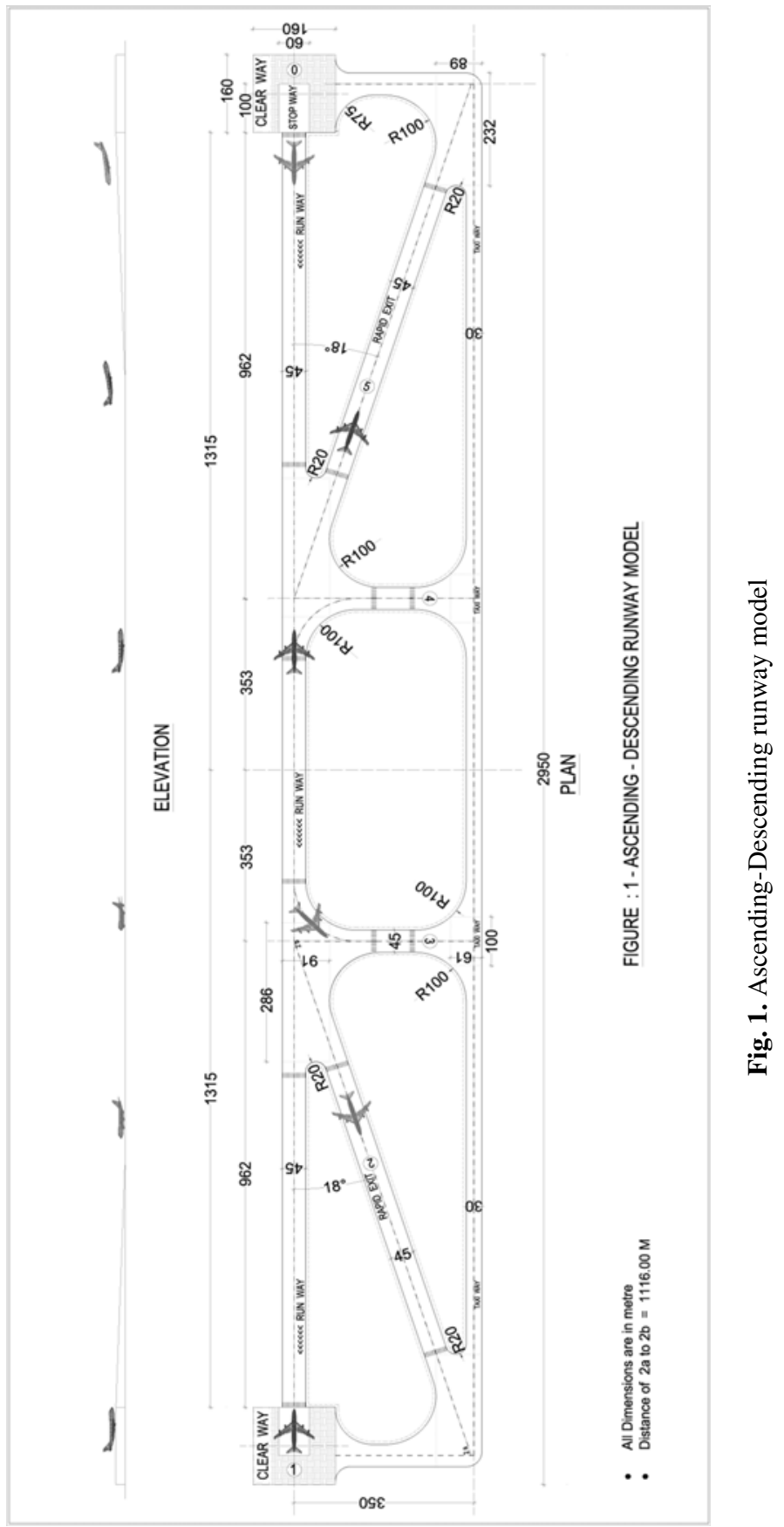




$$
V_{\text {stall }}=\sqrt{\frac{2 m g}{\rho C_{L} S}}
$$

Where

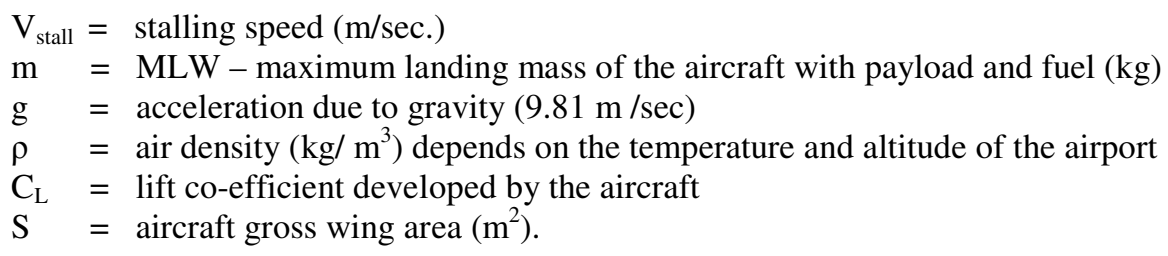

\subsection{First Free Roll}

It is the tangential (arc) distance of transition to touchdown of the aircraft with a minimum sink rate added with the slope run. Upon touchdown the aircraft is allowed to make a free roll to get stabilize after the sinking and retrieval effect of the landing gears. The term $\mathrm{V}_{\mathrm{fl}}$, the flaring velocity is closely related to the stalling speed of the aircraft where the pilots try to maintain a safe margin with the stalling speed for the stability and assurance of the aircraft landing process.

At the end of the flare phase the speed of the aircrafts is supposed to be maintained at $95 \%$ of the stalling speed of the aircraft. In the case of Airbus A380-800 the stall speed is estimated to be $220 \mathrm{kmph}$ or $61 \mathrm{~m} / \mathrm{sec}$. When the pilots or the Instrumental Landing System (ILS) make 2.5 degrees of approach inclination in the descending path of the aircraft, the first free roll distance of the aircraft (neglecting the aerodynamic drag ) is estimated by using the formula

$$
S_{f r 1}=\frac{\left(V_{f l}\right)^{2} \tan \gamma}{g\left[2\left(n_{f}-1\right)+F_{R} \cos \alpha-\sin \alpha\right]}
$$

Where

$\mathrm{n}_{\mathrm{f}}=$ flare load factor (recommended value ranges from 1.1.to 1.3)

$F_{R}=$ rolling and frictional resistance of the runway (assumed as $220 \mathrm{~N} /$ ton mass of the aircraft)

$\alpha=$ runway inclination $(2.5$ degree $)$

The time taken for the first free roll phase is estimated by the equation,

$$
T_{f r 1}=\frac{S_{f r 1}}{V_{f l}}
$$

At the end of the first free roll (approximately after 5 seconds of the touch down) the aircraft is to have the velocity (u) equivalent to 90 to $95 \%$ of the stalling speed. For the aircraft Airbus A-380- 800 it is estimated as $55-58 \mathrm{~m} / \mathrm{sec}$. The aircraft has the capacity to apply brake to decelerate at the rate of 3 to $5 \mathrm{~m} / \mathrm{s}^{2}$. However considering the 
passengers' safety and comfort, pilots would normally decelerate the aircraft well below the maximum braking capacity of the aircraft depending on the length of the runway available. The terminal velocity (v) of the aircraft if it chooses to follow the rapid exit taxi way is to be around $20 \mathrm{~m} / \mathrm{s}$. The minimum and the maximum distance and time required for this phase up to the point of termination of brake / thrust reversal is determined as follows. Figure 2 gives the landing phases of the aircraft.

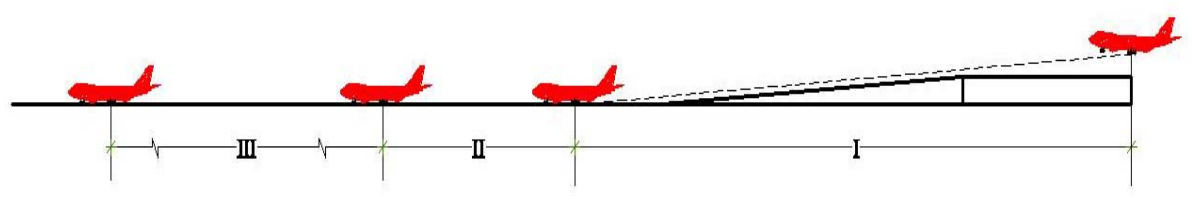

Fig. 2. Verious stages of air craftlanding

\subsection{Decelration (Rrake/Thrust Reversal)}

The long landing run (distance) is determined using the following equations when the initial velocity (u) and the final velocity (v) of the aircraft are known.

$$
\begin{gathered}
v^{2}=u^{2}+2 a s \\
v=u+a t \\
a=g F_{R} \text { (for level ground) } \\
a=g\left(F_{R} \cos \alpha+\sin \alpha\right) \text { (for ascending runway stretch) } \\
a=g\left(F_{R} \cos \alpha-\sin \alpha\right) \text { (for descending runway) }
\end{gathered}
$$

Where

$\mathrm{u}=$ Initial velocity in $\mathrm{m} / \mathrm{s} ; \mathrm{v}=$ Terminal velocity in $\mathrm{m} / \mathrm{s}$

$\mathrm{s}=$ Distance in meters $; \mathrm{a}=$ acceleration in $\mathrm{m} / \mathrm{s}^{2}$

$\mathrm{t}=$ time in seconds $\quad ; \mathrm{F}_{\mathrm{R}}=$ coefficient of runway friction $(0.15$ to 0.2 for rolling , 0.7 for slidinh)

\subsection{Final Roll}

The final roll of the aircraft is subjected to pure frictional resistance offered by the paved main runway or the rapid exit runway. The rolling and sliding frictional resistance generally offered by the paved runway surface would be 0.15 to 0.2 and 0.7 respectively. The distance and the time taken for the final roll is determined taking into account the initial and final velocities as $20 \mathrm{~m} / \mathrm{sec}$ and zero $\mathrm{m} / \mathrm{sec}$ by applying the above equations 6 (a) and 8 . 


\subsection{Take-Off}

The aircraft take-off comprises of two processes as described above. The acceleration required for the aircraft to airborne is around 1.2 to 1.25 times the stalling velocity of the aircraft. The descending runway in a way helps the aircraft to accelerate faster, to reach the required velocity to break contact with the runway and to air lift at the shortest spell. This velocity would be between $264 \mathrm{~km} / \mathrm{hr}$ to $275 \mathrm{Km} / \mathrm{hr}$ for the Airbus 380-800. The aircraft after the clearance from ATC lined up to its position and reach the stop way area of the paved runway to commence its take - off run. By virtue of the fact that the aircraft is placed at the elevated plane of a descending runway (2.5 degree inclination) it starts moving down initially with minimum startup velocity. As the aircraft moves down it gains great momentum due its own mass and steady acceleration. Gradually it picks up the acceleration and attained the required velocity to breaks contact with the runway surface for airlift. The runway length required for the successful take-off is calculated using the equation 6 (a) coupled with equation 9. Even in the event of aborted take-off, the aircraft will have sufficient runway length to decelerate and subsequently claim through the ascending runway at the other end for a definite stop.

\section{Results}

The minimum runway length required of the ascending and descending runway is invariably less by 15 - 20 per cent to the statutory minimum length required of the level runway.

Table 1. Estimation and comparison of Runway lengths

\begin{tabular}{|c|c|c|c|c|c|c|}
\hline Process & Flare & $\begin{array}{l}\text { Free } \\
\text { roll }\end{array}$ & Deceleration & $\begin{array}{l}\text { Final } \\
\text { roll }\end{array}$ & $\begin{array}{l}\text { Total } \\
\text { length } \\
\text { (in metres) }\end{array}$ & $\begin{array}{l}\text { Available } \\
\text { length } \\
\text { (in metres) }\end{array}$ \\
\hline Landing & $\begin{array}{l}344 \\
-514\end{array}$ & $\begin{array}{l}30 \\
-45\end{array}$ & $670-755$ & $\begin{array}{l}90 \\
-136\end{array}$ & 1450 & 2950 \\
\hline Take-off & & & $1935+125$ & & 2060 & \\
\hline
\end{tabular}

\section{Summary}

The innovative concept of ascending and descending runway model provide multiple benefits, such as optimising the runway lengths, saving fuel during landing and takeoff, and subjecting the landing gear to lesser impact and thereby extending its life. Fulfilling the FAA and ICAO's regulatory allowances of $15 \%$ extra on take- off length and $67 \%$ extra on landing length of the runway is also assured with varied runway options for utmost safety. The conceptual design and the model arrived through the four principles of TRIZ is a workable solution for the modern as well as the old airports worldwide. 


\section{Acknowledments}

I am deeply indebted to my Institution Dr. Mahalingam College of Engineering \& Technology for their support to carryout my work on this project at the extended hours of the college. I wish to express my thanks to Mr. K.Senthil Kumar of MIT, Chennai and Dr. J.Shanmugam, Principal, Velammal Engineering College, Chennai for their support of extending the simulation facilities to conduct the second part of the studies on this research.

\section{References}

1. Antonio: Aircraft Runway Length estimation, Part -1 report, Virginia Tech, USA

2. Kim, B.J., et al.: Computer simulation Model for Airplane landing-Performance Prediction. Transportation Research Record (1562)

3. Clarke, et al:: Continuous Descent Approach: Design and Flight Test for Lousiville International Airport. Journal of Aircraft 41(5), 1054-1066 (2004)

4. Domb, E.: The 39 Features of Altshuller's Contradiction Matrix. Triz-Journal (November 1998)

5. Altshuller, G.: The Innovation Algorithm. Technical Innovation Center, Inc. Worcester, MA (2000)

6. Glushkov: Airport Engineering. Mir Publishers, Moscow (1988)

7. Kowalick, J.: Technology forecasting with TRIZ. Triz-Journal (January 2006)

8. Khanna: Airport Planning and Design. Nem Chand \& Bros, Roorkee (2005)

9. Shpakosky, N.: TRIZ in the world of Science. Triz-Journal (March 2008) 